\title{
Development of a 3D-Printable Ultra-High Performance Fiber-Reinforced Concrete for Digital Construction
}

Ravendran Arunothayan ${ }^{1}$, Behzad Nematollahi ${ }^{1 *}$, Ravi Ranade ${ }^{2}$, Shin Hau Bong ${ }^{1}$, Jay Sanjayan $^{1}$

${ }^{I}$ Center for Smart Infrastructure and Digital Construction, Swinburne University of Technology, Hawthorn, VIC 3122, Australia

${ }^{2}$ University at Buffalo, State University of New York, New York, USA

*Corresponding author; Email-bnematollahi@swin.edu.au

\begin{abstract}
This paper presents the systematic development and performance characterization of a nonproprietary 3D-printable ultra-high-performance fiber-reinforced concrete (UHPFRC) for digital construction. Several fresh and hardened properties of the developed 3D-printable UHPFRC matrix (without fiber) and composite (with $2 \%$ volume fraction of steel fibers) were evaluated and compared to that of conventionally mold-cast UHPFRC. Additionally, the effects of testing direction on the compressive and flexural strengths of the printed UHPFRC were investigated. The fresh properties of the UHPFRC developed in this study satisfied the criteria for extrudability, buildability, and shape-retention-ability, which are relevant for ensuring printability. The printed UHPFRC exhibited superior flexural performance to the mold-cast UHPFRC due to alignment of the short fibers in the printing direction. The high compressive and flexural strengths, along with the deflection-hardening behavior, of the developed UHPFRC can enable the production of thin 3D-printed components with significant reduction or complete elimination of conventional steel bars.
\end{abstract}

\section{Keywords}

ultra-high-performance fiber-reinforced concrete (UHPFRC); mechanical properties; extrusion; $3 \mathrm{D}$ concrete printing (3DCP) 


\section{Introduction}

The automation of construction industry by means of Additive Manufacturing (AM) technologies such as 3D-concrete-printing (3DCP) has been gaining attention over the past decade. In the 3DCP technique, a low-slump cementitious material is extruded from a nozzle mounted on a gantry or a robotic arm to print a concrete structure layer-by-layer, similar to the fused deposition modeling (FDM) technique for printing thermoplastics. The 3DCP can improve the quality and speed of construction and eliminate the need for formwork, and thereby the associated labor, resulting in substantial time and cost savings. Furthermore, the layer-bylayer deposition process of 3DCP stimulates geometrical freedom to build complex multifunctional architectures [1-5]. These practical advantages of the 3DCP technique make it valuable for the construction industry.

One of the main restrictions of the extrusion-based 3DCP is the limited variety of 3D-printable concretes. An ideal printable cementitious material should possess low viscosity to allow uninterrupted flow during extrusion and high yield stress to prevent slumping of the material after deposition. At the same time, the material should set quickly to withstand the weight of the subsequent layers deposited above [6]. Few printable concretes with the above combination of properties have been reported in the literature - for example, normal strength concrete [7], geopolymer concrete [8, 9], earth-based mortar [10], and high-performance fiber-reinforced cementitious composite (HPFRCC) [11, 12]. These materials were designed for a specific printer with particular printing configurations (nozzle type and size, flow rate, pumping specifications, etc.) and will likely not work elsewhere due to change in material constituents or printing configuration. Therefore, application-specific cementitious materials should be systematically developed for extrusion-based 3DCP.

Several researchers have used fibers in concrete to overcome the challenge of using conventional steel reinforcement with the printing process. For instance, polypropylene (PP) micro fibers have been used in the 3D-printable HPFRCC to reduce shrinkage and deformation 
in the plastic state $[11,12]$. In a previous study, the authors of this paper showed that the 3Dprinted geopolymers containing $0.75 \%$ and $1 \%$ (by volume) of PP fibers exhibited deflectionhardening behavior in bending [13]. Panda et al. [14] investigated the effects of short glass fiber on the mechanical properties of 3D-printed geopolymer concrete. Bos et al. [15] used short straight steel fibers to improve ductility of the normal strength 3D-printed concrete. Although partial reduction of conventional reinforcement (meant for shrinkage, temperature changes, and crack control) has been demonstrated in the previous studies, substantial reduction or complete elimination of conventional steel bars requires printable concretes with significantly greater flexural and tensile strengths.

This study aims to systematically develop a printable ultra-high performance fiber reinforced concrete (UHPFRC) to address the above-mentioned challenges of 3DCP. The ultra-high compressive strength of the UHPFRC enables the printing of complex volumetric profiles with slender cross sections, thereby fully utilizing the geometric freedom offered by the 3DCP technology. In addition, very high flexural strength with a deflection-hardening behavior of the UHPFRC significantly reduces the dependence on the conventional steel bars. Although an ultra-high-performance concrete (UHPC) matrix (without fibers) has been printed before [16] the printing of UHPFRC has not been reported so far. In addition, the reported printable UHPC had a proprietary formulation and its design was not reported. Thus, this research demonstrates the systematic development and 3D-printing of UHPFRC for the first time in the literature.

The fresh and hardened properties of the developed 3D-printable UHPFRC were reported in this article. Fresh properties of extrudability and buildability were assessed qualitatively, whereas workability and shape-retention-ability were quantified experimentally. Hardened properties, including apparent porosity, bulk density, compressive strength, flexural strength and interlayer bond strength, of the printed UHPFRC matrix (without fiber) and composite (with fiber) were determined through standard tests. The hardened properties of the printed UHPFRC were also compared with those of the conventionally mold-cast UHPFRC. In addition, the effects of testing direction on the mechanical properties of the printed UHPFRC were investigated. The 
practical applicability of the developed UHPFRC was validated by 3D-printing a relatively large component with a complex geometry.

\section{Materials and mix proportions}

In this research, the binder for the UHPFRC consisted of general purpose (Type GP) Portland cement, conforming to AS 3972 [17] and silica fume (micro silica), conforming to AS 3582 [18] with specific surface area of $18 \mathrm{~m}^{2} / \mathrm{g}$. The chemical compositions of cement and silica fume are presented in Table 1.

Table 1 Chemical compositions of cement and silica fume

\begin{tabular}{|c|c|c|}
\hline Oxides (wt\%) & Cement $^{1}$ & Silica fume $^{2}$ \\
\hline $\mathrm{Al}_{2} \mathrm{O}_{3}$ & 4.47 & 0.33 \\
\hline $\mathrm{SiO}_{2}$ & 20.34 & 98.4 \\
\hline $\mathrm{CaO}$ & 62.91 & 0.01 \\
\hline $\mathrm{Fe}_{2} \mathrm{O}_{3}$ & 4.58 & 0.31 \\
\hline $\mathrm{K}_{2} \mathrm{O}$ & 0.29 & 0.01 \\
\hline $\mathrm{MgO}$ & 1.24 & -- \\
\hline $\mathrm{Na}_{2} \mathrm{O}$ & 0.31 & 0.01 \\
\hline $\mathrm{P}_{2} \mathrm{O}_{5}$ & -- & 0.2 \\
\hline $\mathrm{TiO}_{2}$ & -- & 0.01 \\
\hline $\mathrm{SO}_{3}$ & 2.58 & -- \\
\hline LOI* & 3.27 & 1 \\
\hline \multicolumn{3}{|c|}{$*$ LOI $=$ Loss on ignition } \\
\hline \multicolumn{3}{|c|}{${ }^{1}$ Adopted from [7] } \\
\hline
\end{tabular}

Three types of sieve graded silica sands - each with different particle sizes - were used in this study. The fine, medium, and coarse silica sands had median particle sizes $\left(\mathrm{D}_{50}\right)$ of $176 \mu \mathrm{m}, 498$ 
$\mu \mathrm{m}$, and $840 \mu \mathrm{m}$ respectively. A polycarboxylate ether-based superplasticizer (SP) was used to adjust the workability. Sodium carboxymethyl cellulose water-soluble polymer powder was used as a viscosity modifying agent (VMA) to adjust the rheological properties of the mixture with respect to $3 \mathrm{D}$ printing process. Brass-coated short straight steel fibers with the properties given in Table 2 were used in the UHPFRC at a volume fraction of $2 \%$.

Table 2 Properties of steel fibers

Diameter $(\mu \mathrm{m}) \quad$ Length $(\mathrm{mm}) \quad$ Young's modulus (GPa) Density $\left(\mathrm{g} / \mathrm{cm}^{3}\right) \quad$ Strength (MPa)

200

13

200

7.85

2500

Two types of methods were used to quantify the particle size distributions of the dry granular raw materials. Sieve analysis as per ASTM C136 [19] was carried out for all three types of sands. Particle size distributions of cement and silica fume were measured using the laser ultrasonication technique with a particle size analyzer. The particle size distributions of the dry granular materials are shown in Figure 1. 


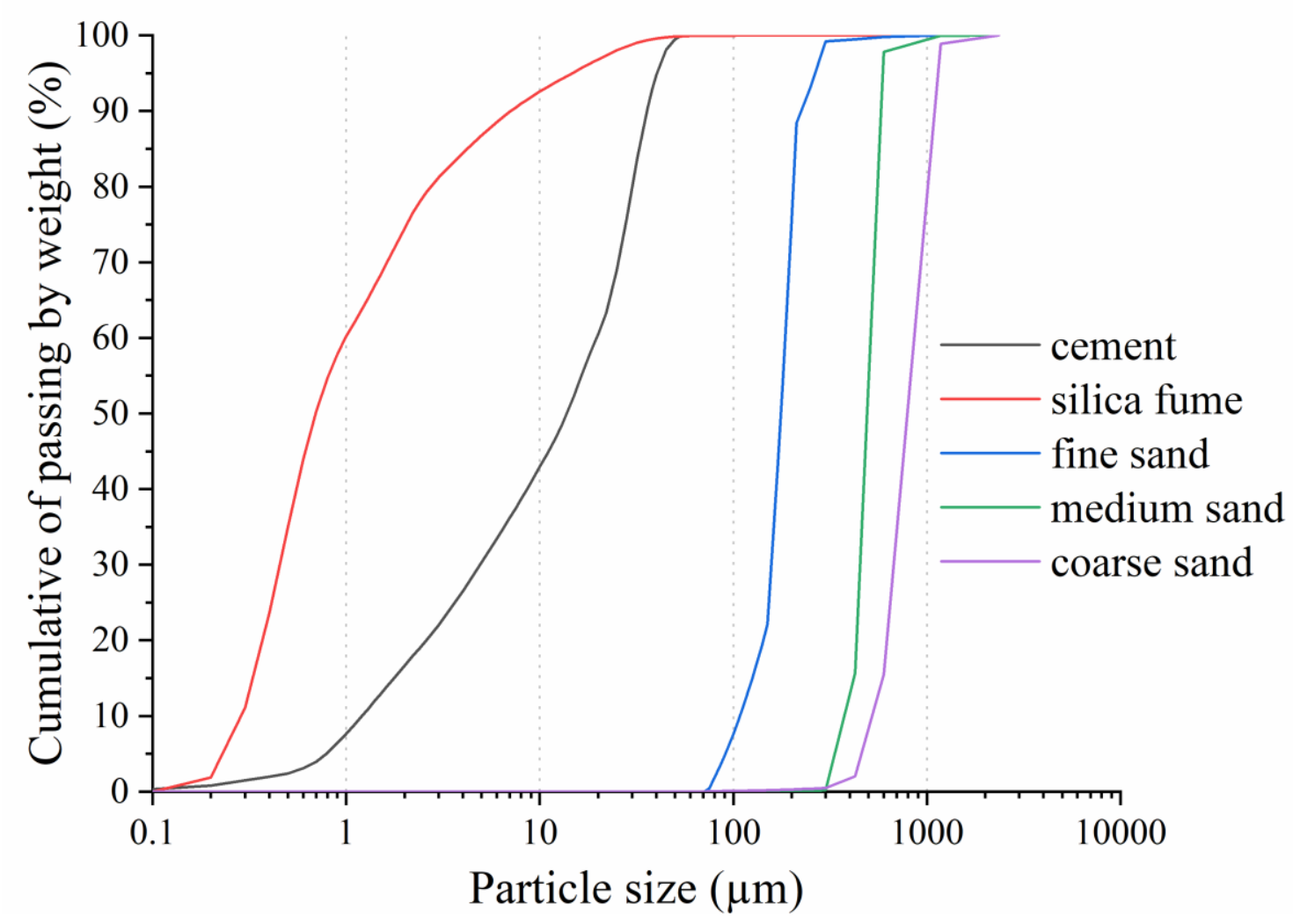

Figure 1 Particle size distribution of granular materials

The mix proportions of the UHPFRC matrix were calculated using the modified Andreasen and Anderson (modified A\&A) [20] model for maximizing the particle packing density of the dry materials. The modified A\&A packing model has been successfully applied for the mixture optimization in the design of conventional concrete [21], lightweight concrete [22] and selfcompacting concrete [23]. Ragalwar et al. [24] investigated the influence of the distribution modulus $(q)$ on the properties of the UHPFRC matrix. Yu et al. [25] recommended the value of $q=0.23$ for the production of UHPFRC mixes. The mathematical equation for the target particle size distribution curve in the modified A\&A model is presented in Equation 1.

$P_{t a r}(D)=\frac{D^{q}-D_{\min }^{q}}{D_{\max }^{q}-D_{\min }^{q}}$

where $D$ is the particle size, $P_{t a r}(D)$ is the ratio of total dry particles with diameter smaller than $\mathrm{D}, D_{\max }$ and $D_{\min }$ are the maximum and minimum particle sizes of the mix, respectively. The 
parameter $q$ is called the distribution modulus, which controls the curvature of the $P_{\text {tar }}(D)$.

Physically, $q$ represents the fraction between the coarse and fine particles of the mixture. In general, greater $q$ leads to a coarser mixture. The $P_{\text {tar }}(D)$ used in this study utilized $D_{\max }$, $D_{\min }$, and $q$ of $1.2 \mathrm{~mm}, 0.1 \mu \mathrm{m}$, and 0.23 , respectively. The proportions of ingredients were iteratively calculated by minimizing the sum of squared-error between $P_{t a r}(D)$ and the composite particle size distribution at discrete particle sizes. The target curve and the composite particle size distribution of the UHPFRC matrix are presented in Figure 2.



Figure 2 UHPFRC mix design curve vs. modified A\&A target curve

Several trials of the UHPFRC matrix and composite were conducted for determining the appropriate SP and VMA contents to satisfy the extrudability, buildability, and workability requirements. The mix proportions of the printable UHPFRC are presented in Table 3. 
Table 3 Mix proportions of the printable UHPFRC

\begin{tabular}{cccccccccc}
\hline \multicolumn{2}{c}{ Binder } & \multicolumn{3}{c}{ Silica sand } & \multirow{2}{*}{ Water } & SP & VMA & Fiber \\
\cline { 1 - 6 } Cement & Silica fume & Fine & Medium & Coarse & & & & \\
& & & & & & & & & \\
\hline 0.7 & 0.3 & 0.4 & 0.3 & 0.3 & 0.16 & 0.015 & 0.003 & $2 \%$
\end{tabular}

Note: All numbers are mass ratios of the binder weight, except the fiber content (volume fraction).

\section{Experimental methods}

\subsection{Mixing}

A 20L Hobart mixer was used for mixing. First, dry materials were mixed for 5 minutes.

Approximately $75 \%$ of the water was added and mixed for 5 additional minutes. At this point, the remaining water was mixed with the SP and gradually added to the mixture. The mixing was continued for another 9 minutes until a good rheology was achieved for facilitating homogeneous fibers dispersion. The fibers were then gradually added and mixed for 10 minutes. Finally, the VMA powder was added and mixed for an additional minute. The total mixing time was 30 minutes. Visual assessment by the authors confirmed the absence of fiber segregation in the fresh mixture.

\subsection{Printing and casting}

As shown in Figure 3 (a), a small-scale custom-made 3D printer was used in this study to simulate the extrusion-based 3DCP process. A piston type extruder having a $45^{\circ}$ nozzle opening of $30 \mathrm{~mm}(\mathrm{~W}) \times 15 \mathrm{~mm}(\mathrm{H})$ was used in the printer. The extruder was a metallic cylinder with a diameter of $50 \mathrm{~mm}$ and a length of $600 \mathrm{~mm}$. Figure 3 (b) shows the extrusion of the printable UHPFRC matrix through the nozzle. Two-layer specimens measuring $30 \mathrm{~mm}(\mathrm{~W}) \times 30 \mathrm{~mm}(\mathrm{H})$ $\times 280 \mathrm{~mm}(\mathrm{~L})$ were printed at a constant speed with a print-time interval (delay time) of 2 minutes. In addition, $25 \mathrm{~mm}$ cubes and prisms with the dimensions of $25 \mathrm{~mm} \times 25 \mathrm{~mm} \times 280$ $\mathrm{mm}$ were conventionally mold-cast for comparison purposes. It should be noted that the mixture 
proportions and mixing procedure of the conventionally mold-cast specimens were identical to those of the printed specimens.
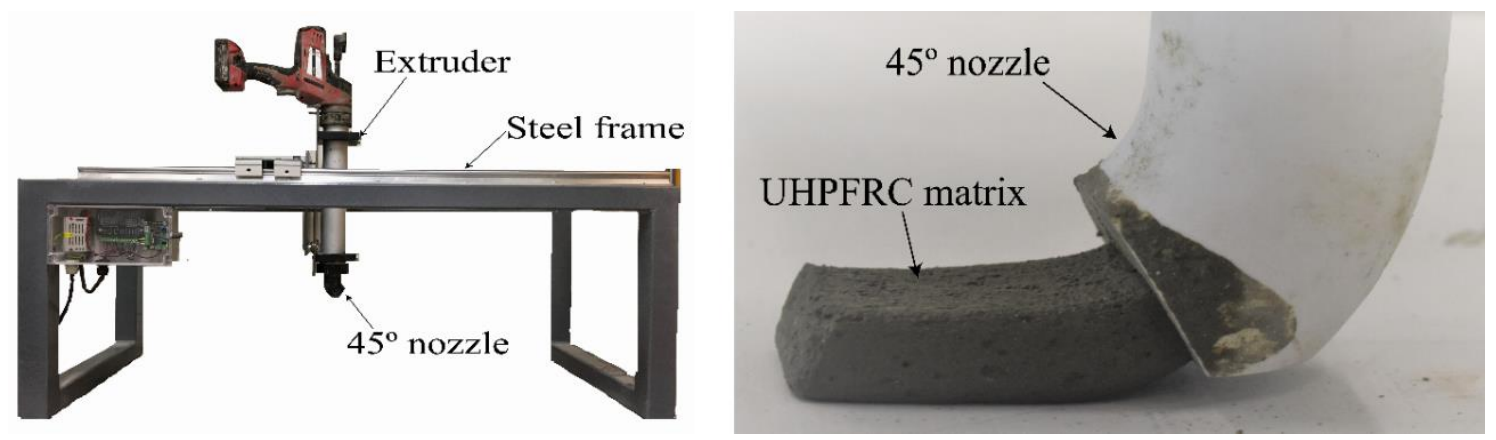

Figure 3 (a) Small-scale custom-made 3D printer used in the study, (b) Extrusion of 3Dprintable UHPFRC matrix

\subsection{Curing}

After completion of the printing process, the printed specimens were immediately placed inside a sealed container for 24 hours to reduce water loss. The conventionally mold-cast specimens were covered with plastic sheets and de-molded after 24 hours. An elevated temperature curing procedure was adopted in this study to accelerate the hydration reactions. At the end of 24 hours, all printed and mold-cast specimens were transferred to a water tank and cured at the room temperature $\left(20 \pm 3^{\circ} \mathrm{C}\right)$ for seven days. The specimens were then put inside an oven and heat cured for four days in water at $90^{\circ} \mathrm{C}$, followed by two days in air at $90^{\circ} \mathrm{C}$. According to Ranade et al. [26], the 14-day compressive strength of the samples cured using the above procedure is equivalent to the 90-day compressive strength of the samples cured in the ambient conditions. At the end of the accelerated curing process, the surfaces of the printed specimens were ground to have flat surfaces for testing.

\subsection{Test methods}

\subsubsection{Fresh properties}


Flow tests in accordance with ASTM C1437 [27] were conducted to measure the workability of the fresh UHPFRC matrix and composite. Two orthogonal diameters of the mixture flow were recorded before and after the drops of the flow table.

A qualitative method was adopted to evaluate the extrudability of the UHPFRC matrix and composite through a piston type extruder. The acceptance criterion for the extrudability test was the successful extrusion of five single layers (not stacked) of the fresh mixtures through the nozzle without any obstruction such as blockage, tearing, segregation or bleeding. Each of the five layers was at least $250 \mathrm{~mm}$ long with a cross-section of $30 \mathrm{~mm}(\mathrm{~W}) \times 15 \mathrm{~mm}(\mathrm{H})$ extruded using the small-scale printer with a piston type extruder (described in section 3.2). Similar approaches were used elsewhere $[8,11]$ to evaluate extrudability.

Similar to the extrudability test, a qualitative method was adopted to evaluate the buildability of the UHPFRC matrix and composite. Seven layers of the UHPFRC matrix and composite were printed using the small-scale printer (described in section 3.2). Each layer had the dimensions of $15 \mathrm{~mm}(\mathrm{H}) \times 30 \mathrm{~mm}(\mathrm{~W}) \times 280 \mathrm{~mm}(\mathrm{~L})$ and the delay time between layer depositions was approximately 2 minutes. The acceptance criterion for buildability was the successful layer upon layer build-up of the fresh mixtures without any vertical distortion, layer failure or excessive deformation of the lower layers.

A quantitative test was set up to determine the shape-retention-ability (SRA, i.e. the ability of the fresh mixtures to hold their shapes after extrusion). In each test, the fresh mixture was filled into a plastic cylinder of $60 \mathrm{~mm}$ diameter and $60 \mathrm{~mm}$ height and tamped lightly. The plastic cylinder was lifted after two minutes (to simulate the delay time of 2 minutes used in the printing process) and the SRA of the freestanding mixtures was monitored using a camera. The fresh UHPFRC composite sample immediately after lifting of the plastic cylinder is shown in Figure 4. Circular steel plates of $60 \mathrm{~mm}$ diameter, each weighing 170 grams were loaded gradually one after the other on top of the freestanding fresh mixture until its failure. Before the application of circular steel plates, a plastic plate measuring $100 \mathrm{~mm}$ in diameter and 10 grams in weight was gently placed on top of the fresh mixture to distribute the pressure uniformly on 
the fresh mixture. The images of the fresh samples were recorded at each stage of loading using the camera. These images were then processed digitally to quantify the change in diameter and height of the fresh sample.

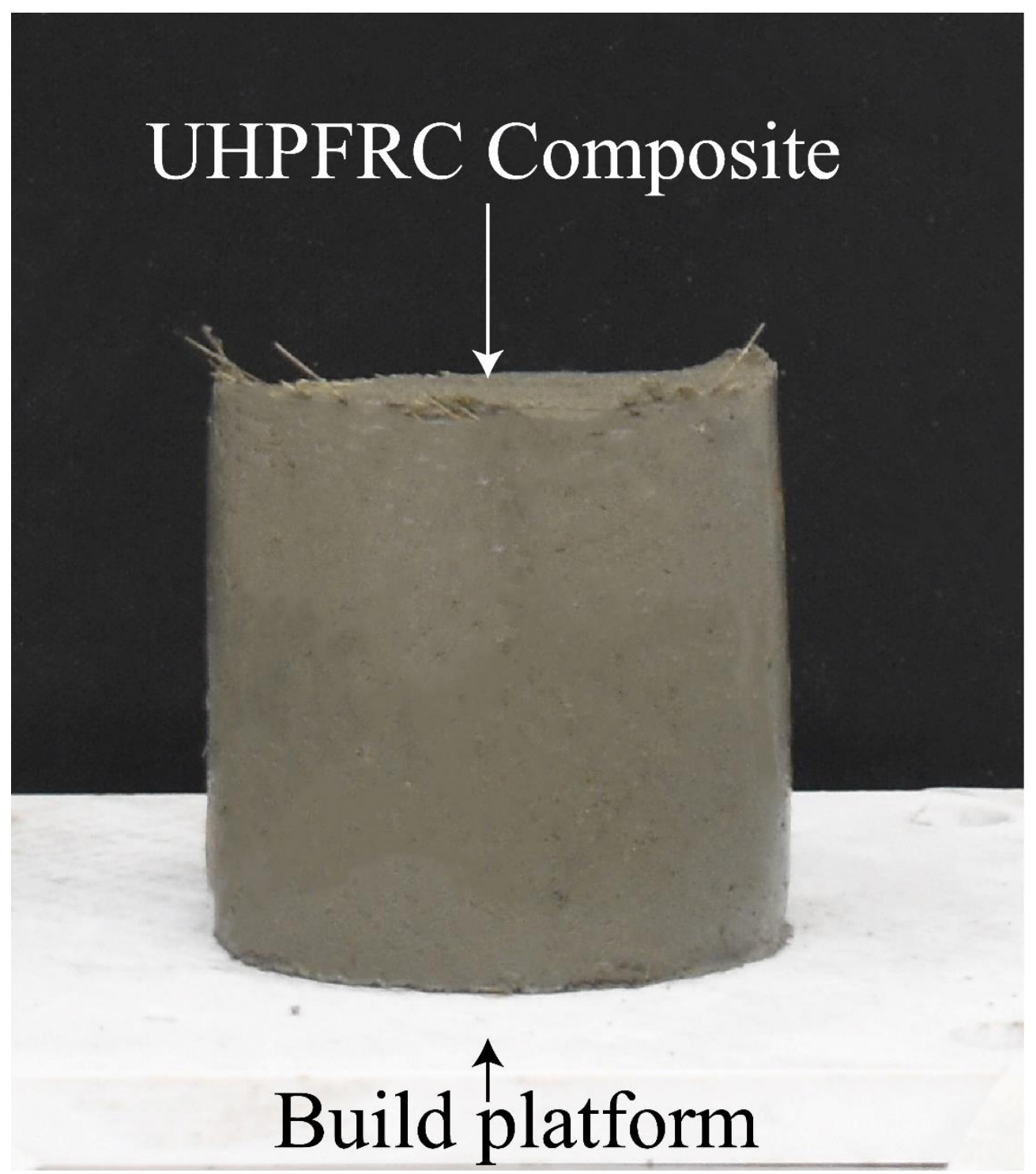

Figure 4 Fresh UHPFRC composite sample immediately after lifting of the plastic cylinder for determining the shape-retention-ability 
The SRA of the fresh UHPFRC matrix and composite is defined in Equation 2. SRA and $\mathrm{SRA}_{h}$ determine the dimensional variations with respect to the diameter and the height of the UHPFRC sample, respectively.

$$
S R A_{d}=\frac{d_{L}}{d} ; S R A_{h}=\frac{h_{L}}{h}
$$

where $h_{L}, d_{L}$ are the height and diameter of the bottom of the freestanding UHPFRC sample at a given load $L$ and $h, d$ are the height and diameter of the bottom of the freestanding UHPFRC sample before load application.

\subsubsection{Hardened properties}

To measure the compressive strength of the printed UHPFRC matrix and composite, $25 \mathrm{~mm}$ cube specimens were extracted from the printed specimens by sawing and were loaded in three directions as shown in Figure 5. At least six printed cubes were prepared for testing in each direction. To compare the compressive strength of the printed UHPFRC with that of the moldcast UHPFRC, at least six $25 \mathrm{~mm}$ mold-cast cube specimens were also tested. A constant load rate of $0.33 \mathrm{MPa} / \mathrm{s}$ was applied for all the compression tests.

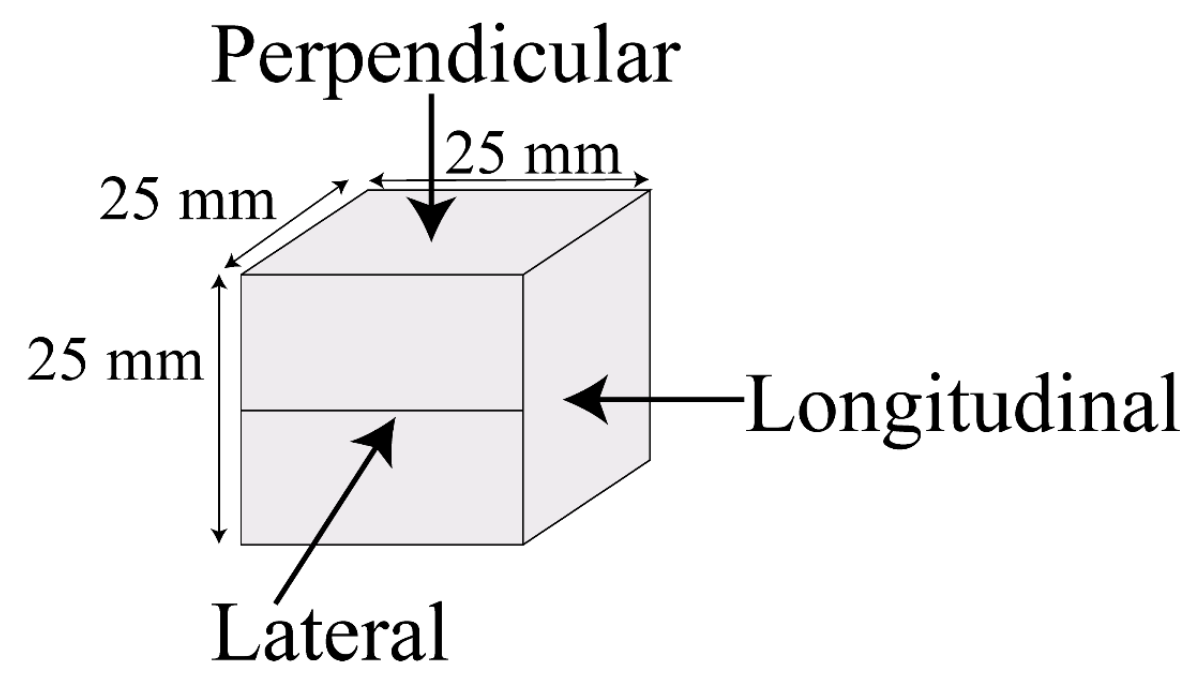

Figure 5 Loading directions for compression test of printed specimen (not to scale) 
To measure the modulus of rupture (MOR or flexural strength) of the printed UHPFRC matrix and composite, $280 \mathrm{~mm} \times 25 \mathrm{~mm} \times 25 \mathrm{~mm}$ printed specimens were tested in the perpendicular and lateral directions. At least six specimens were prepared for testing in each direction. Similar to the compression tests, at least six mold-cast specimens with the dimensions of $280 \mathrm{~mm} \times 25$ $\mathrm{mm} \times 25 \mathrm{~mm}$ were prepared to compare the MOR of the printed UHPFRC with that of the mold-cast UHPFRC. A three-point flexure test with a span of $160 \mathrm{~mm}$ and a displacement control rate of $1 \mathrm{~mm} / \mathrm{min}$ was used. Figure 6 shows the loading directions of the flexural test specimens.

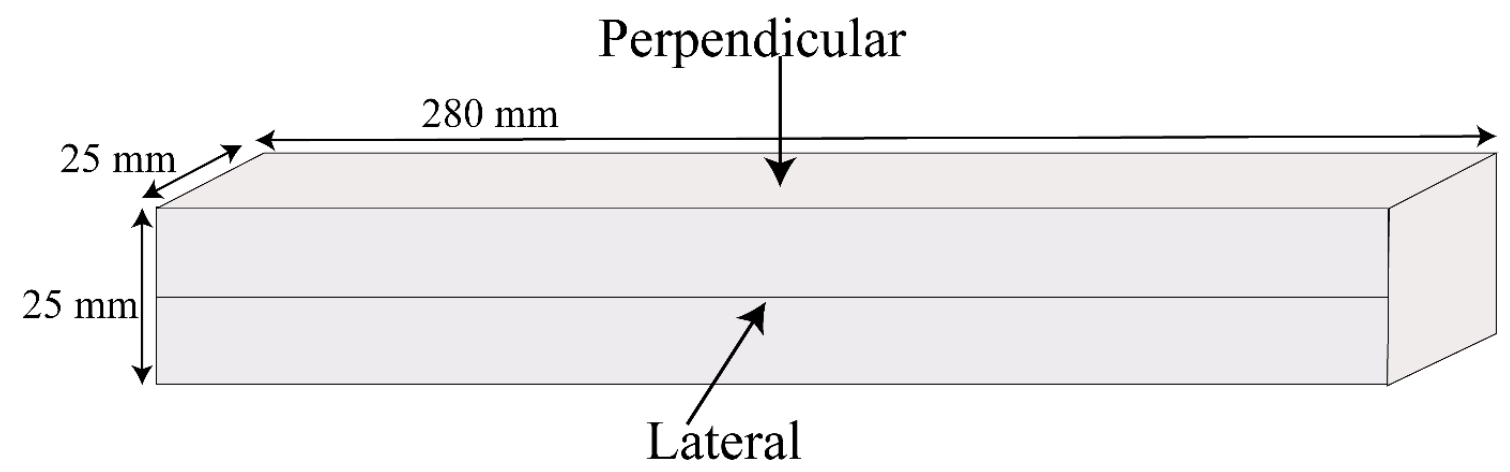

Figure 6 Loading directions for flexural test of printed specimen (not to scale)

To measure the inter-layer bond strength of the UHPFRC matrix and composite, at least six 50 $\mathrm{mm} \times 25 \mathrm{~mm} \times 25 \mathrm{~mm}$ specimens were sawn from the printed layers. Two T-shape metallic brackets were glued to the top and the bottom of each specimen using an epoxy so that the specimens could be hung under uniaxial pull-out load without shear support. In addition, small notches of $5 \mathrm{~mm}$ depth (see Figure 7) were cut from the edges at the layer interface to increase the probability of the failure at the interface. The specimen was pulled in the direction 
perpendicular to the layer interface under displacement control at the rate of $1 \mathrm{~mm} / \mathrm{min}$. Care was taken to eliminate eccentricity while aligning the specimens vertically.

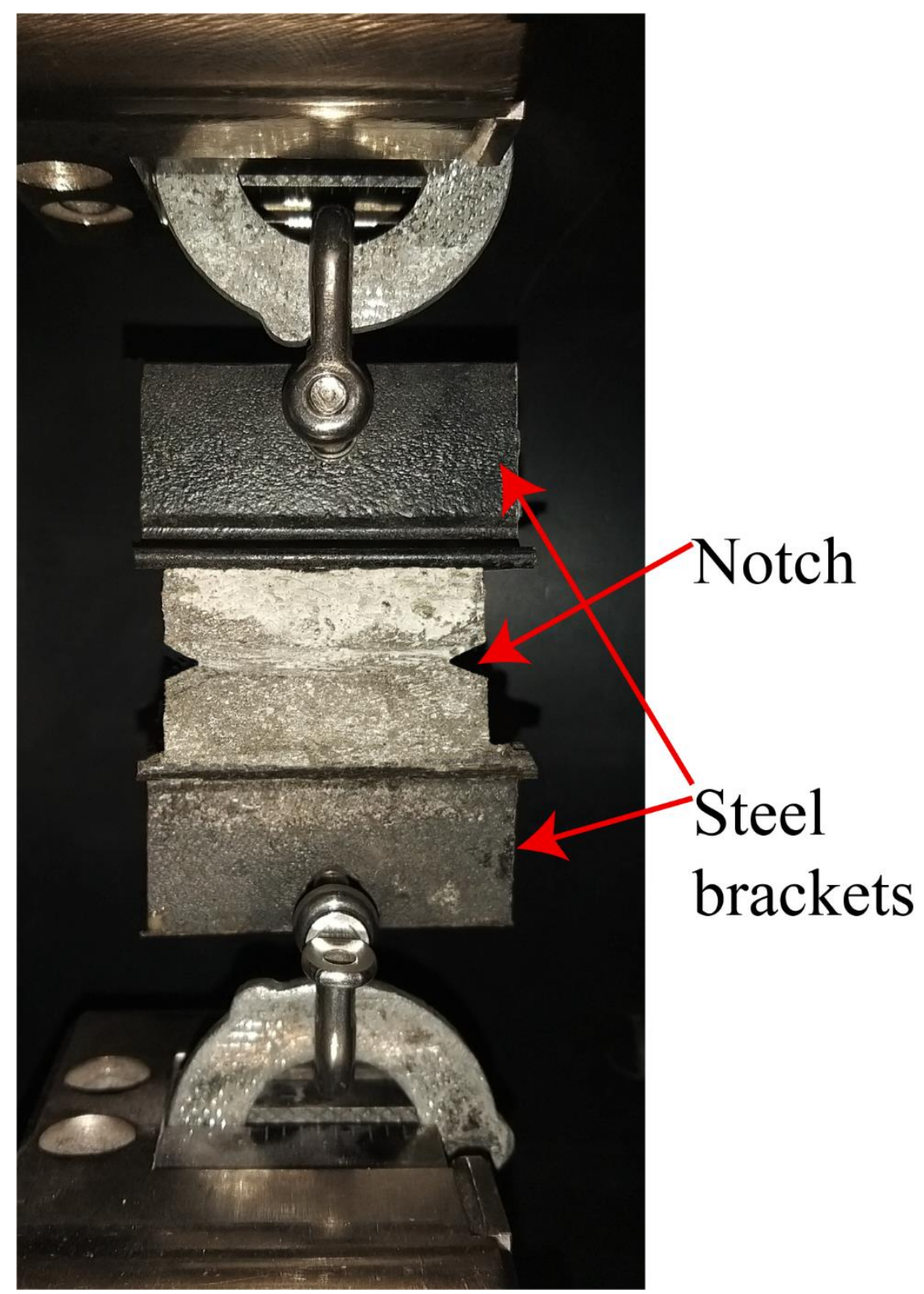

Figure 7 Inter-layer bond strength test setup

The apparent porosity and bulk density of the hardened UHPFRC matrix and composite were measured in accordance with ASTM C20 [28]. For each mixture, at least six specimens were collected from the residual pieces of the UHPFRC specimens tested under flexure. Details of the test can be found in Nematollahi et al. [13]. The apparent porosity and bulk density of each 
UHPFRC mixture was calculated according to [28]. These properties of the mold-cast UHPFRC matrix and composite were also measured for comparison.

\section{Results and Discussion}

\subsection{Fresh properties}

The flow (spread diameter) of UHPFRC matrix and composite are presented in Figure 8. The spread diameters of the UHPFRC matrix and composite before drop of the flow table were close to the bottom diameter of the mini-slump cone used in this study $(100 \mathrm{~mm})$, indicating the fresh mixtures had almost zero slump before drop of the flow table, which is desirable for extrusionbased 3DCP. The spread diameter after the drop of the flow table satisfies the printability region recommended in [29]. As expected, the workability was slightly reduced with the addition of the fibers due to weak adhesive forces between the fibers and the matrix and increase in the surface area per unit volume of the composite that slightly increases the adsorption of the mix water. 


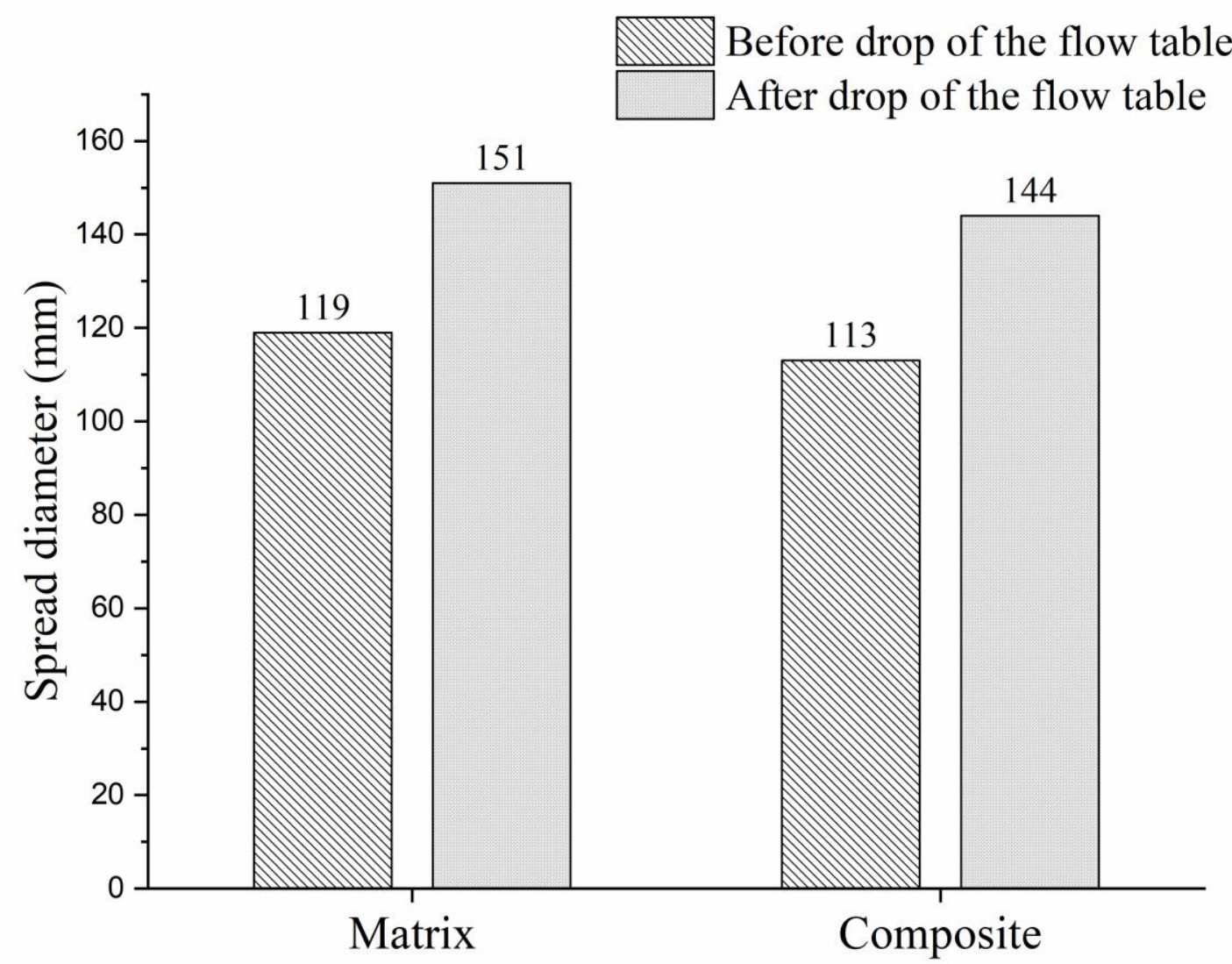

Figure 8 Flow test results of the UHPFRC matrix and composite

Figure 9 shows five singly printed layers of the UHPFRC matrix and composite, each having a length of at least $250 \mathrm{~mm}$. No blockage, tearing, segregation or bleeding was observed during the extrusion process, which indicates the developed UHPFRC matrix and composite passed the extrudability criterion. Figure 10 shows seven stacked printed layers of the UHPFRC matrix and composite. No vertical distortion, layer failure or excessive deformation of the lower layers was observed, which indicates the developed UHPFRC matrix and composite passed the buildability criterion. 


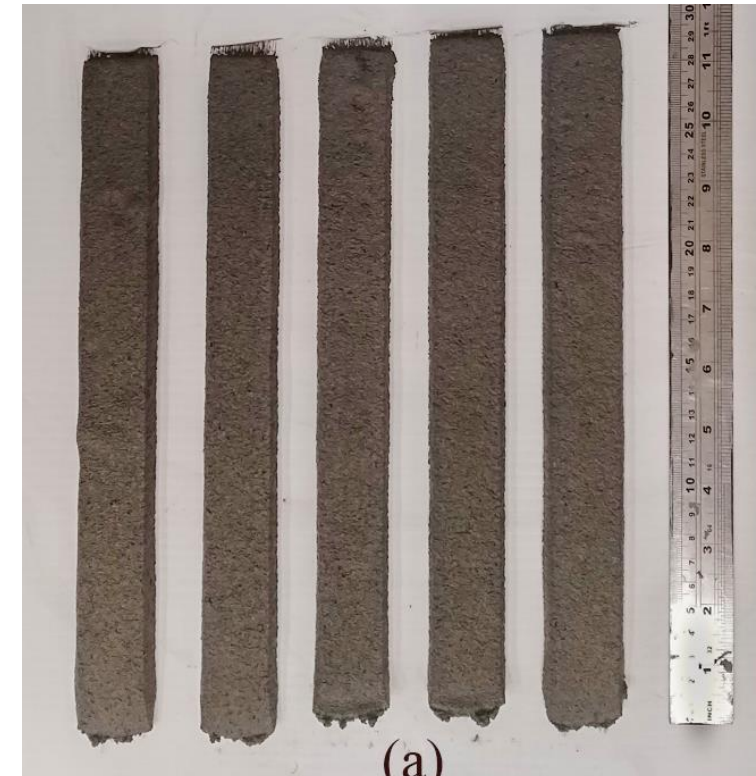

(a)

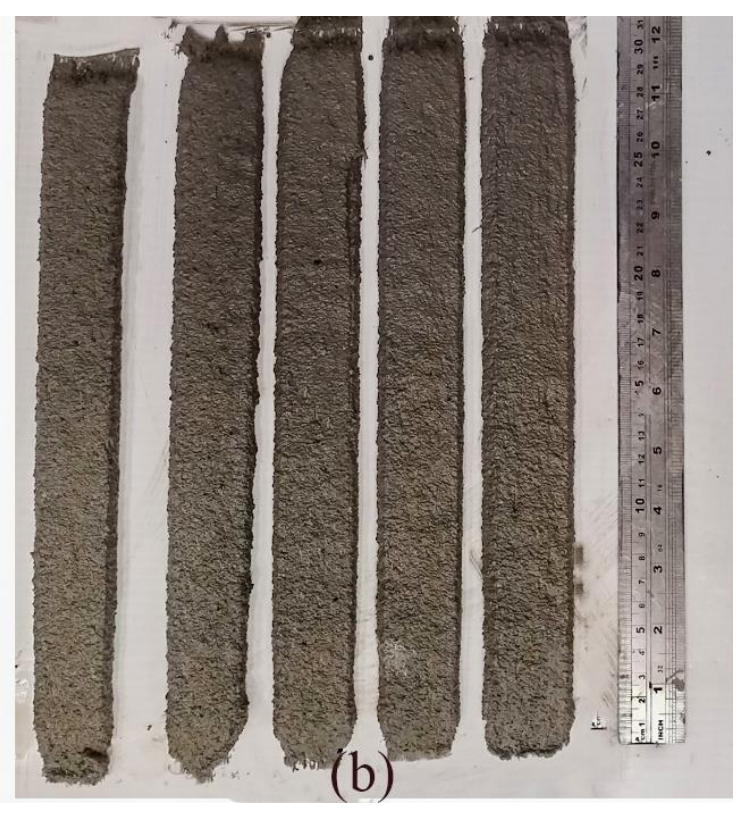

Figure 9 Extrudability test results of the printable UHPFRC: (a) matrix; and (b) composite
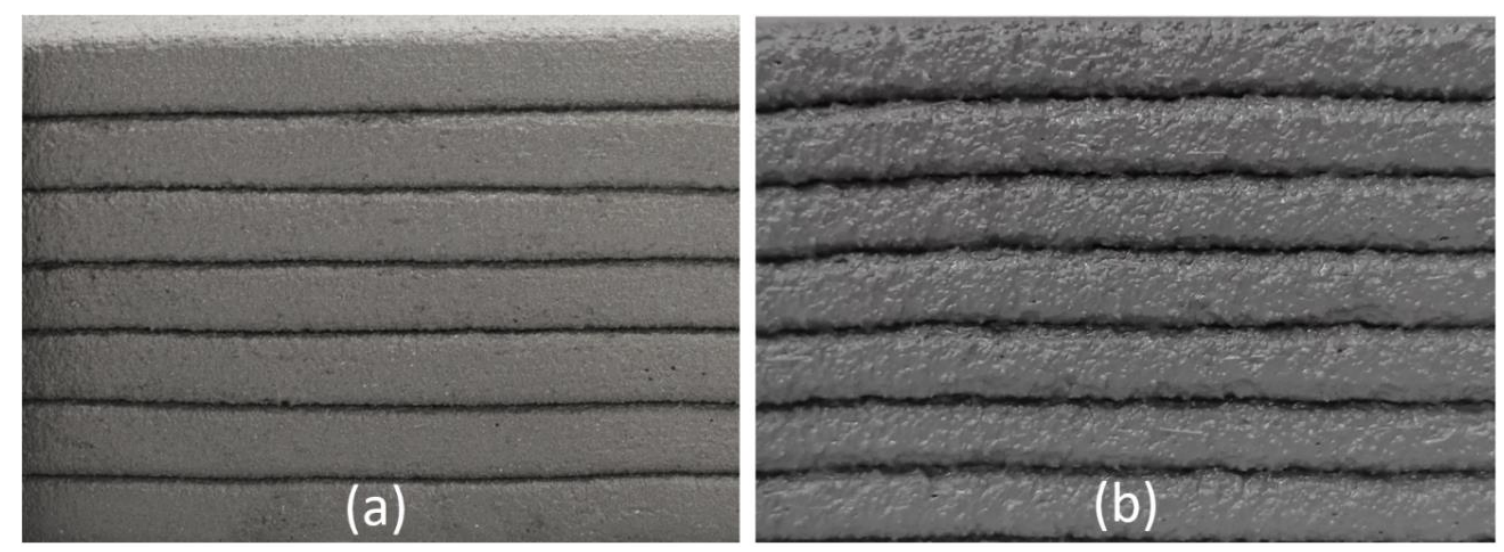

Figure 10 Buildability test results of the printable UHPFRC: (a) matrix; and (b) composite

Figure 11 shows the photos of the UHPFRC matrix and composite samples under increasing vertical load for testing their SRA. Figure 12 plots the SRA indices $\left(\mathrm{SRA}_{1}\right.$ and $\left.\mathrm{SRA}_{2}\right)$ of the UHPFRC matrix and composite as a function of the vertical load. Both the horizontal and vertical distortions $\left(\mathrm{SRA}_{1}\right.$ and $\left.\mathrm{SRA}_{2}\right)$ of the UHPFRC composite were smaller than those of the UHPFRC matrix at all vertical loads. It can also be observed that the UHPFRC matrix sample failed at a vertical load greater than about $0.7 \mathrm{~kg}$, which is lower than the load carried by the UHPFRC composite sample $(1.2 \mathrm{~kg})$. Therefore, the use of fibers improves SRA and increases the vertical load capacity of the fresh mixture. 

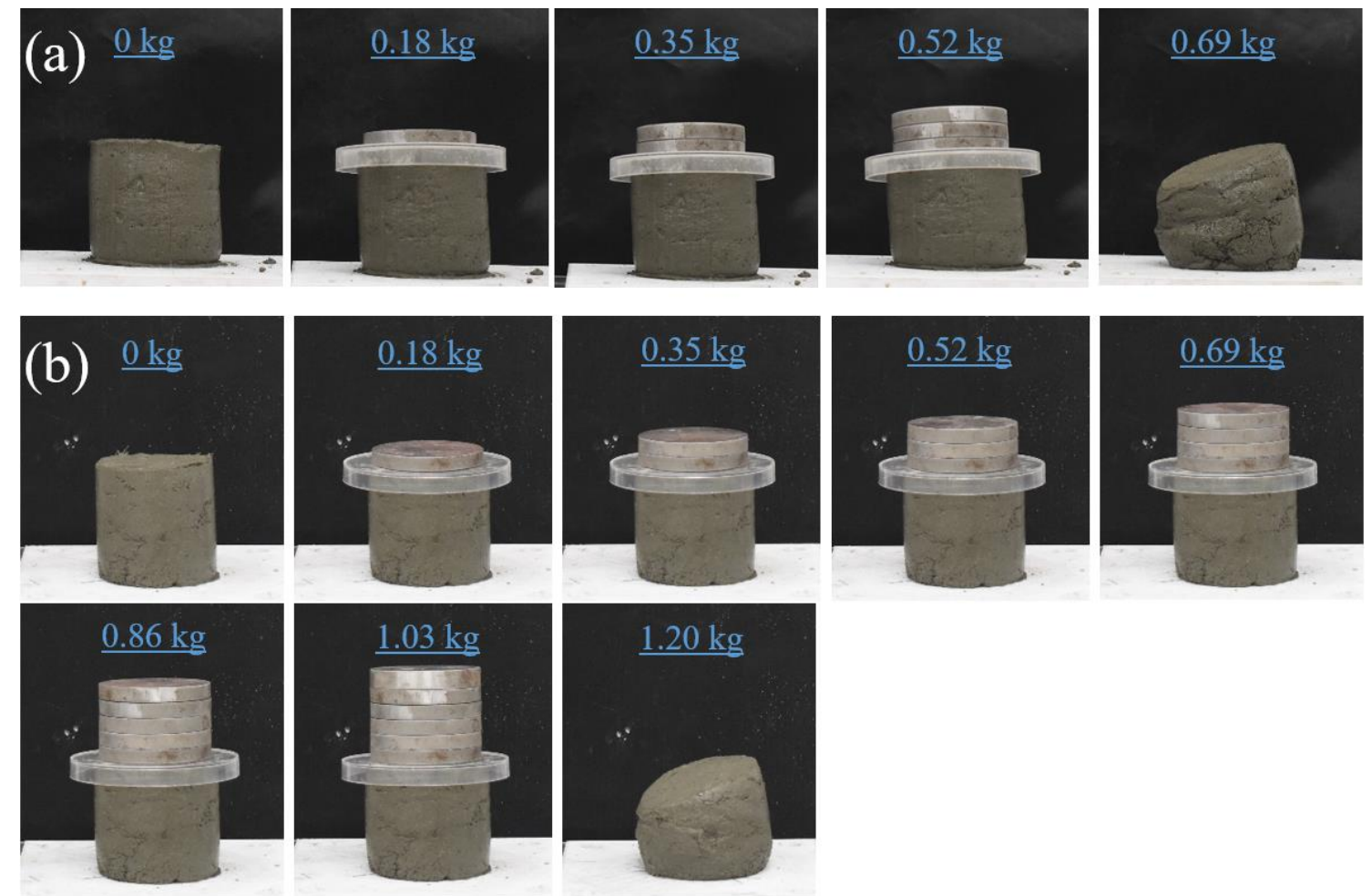

Figure 11 Shape-retention-ability test results of the printable UHPFRC: (a) matrix; and (b) composite

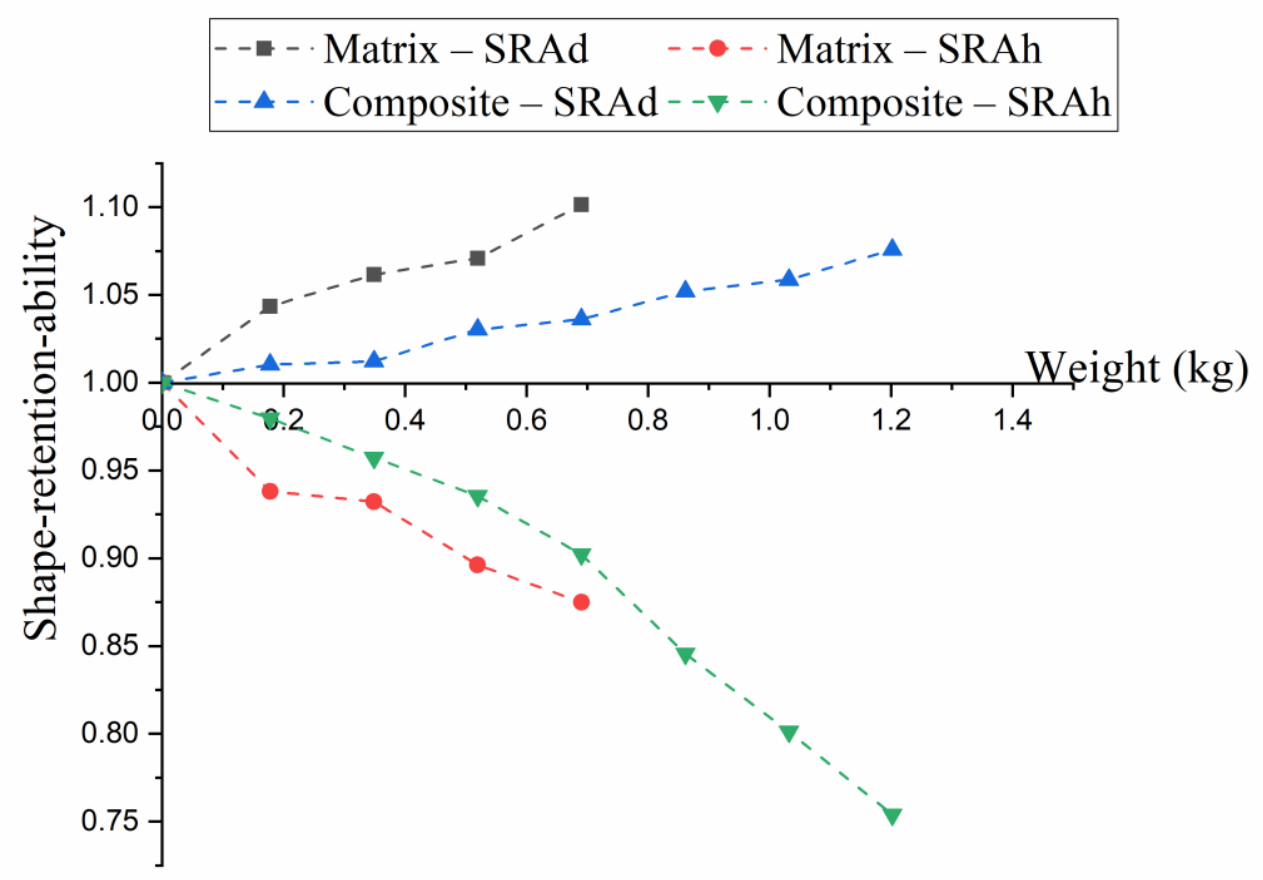

Figure 12 Shape-retention-ability indices of the printable UHPFRC matrix and composite 


\subsection{Hardened properties}

Figure 13 presents the results of the compression tests. The compressive strength of the moldcast UHPFRC was higher than that of the 3D-printed UHPFRC in all loading directions. This is explained by the greater porosity of the printed UHPFRC due to lack of confinement and vibration (during printing) compared to the mold-cast UHPFRC (see Figure 19). The apparent porosity and bulk density results of both mold-cast and 3D-printed UHPFRC are presented in the subsequent section. The compressive strength of the printed UHPFRC is dependent on the loading direction. The pressure exerted during the extrusion process contributes to improved compaction of the UHPFRC in the longitudinal direction. As a result, the highest compressive strength is obtained in the longitudinal direction. In contrast, due to negligible confinement in the lateral direction (in-plane of the layer but perpendicular to the printing direction), the lowest compressive strength is observed in this direction. Due to the weight of the top layer, the bottom layer of the printed UHPFRC is slightly compacted. This results in larger compressive strength in the direction perpendicular to the layers, but it is still smaller than the compressive strength in the longitudinal direction. It should be pointed out that the anisotropic behavior of the printed UHPFRC is an inherent feature of the layer-by-layer manufacturing process. The quantitative difference in the strength values in different directions generally depend on many parameters including printing configurations and printing materials [30]. Similar anisotropic behavior has been reported in the literature for normal strength concrete [7], high performance concrete [12] and geopolymers $[8,13]$. 


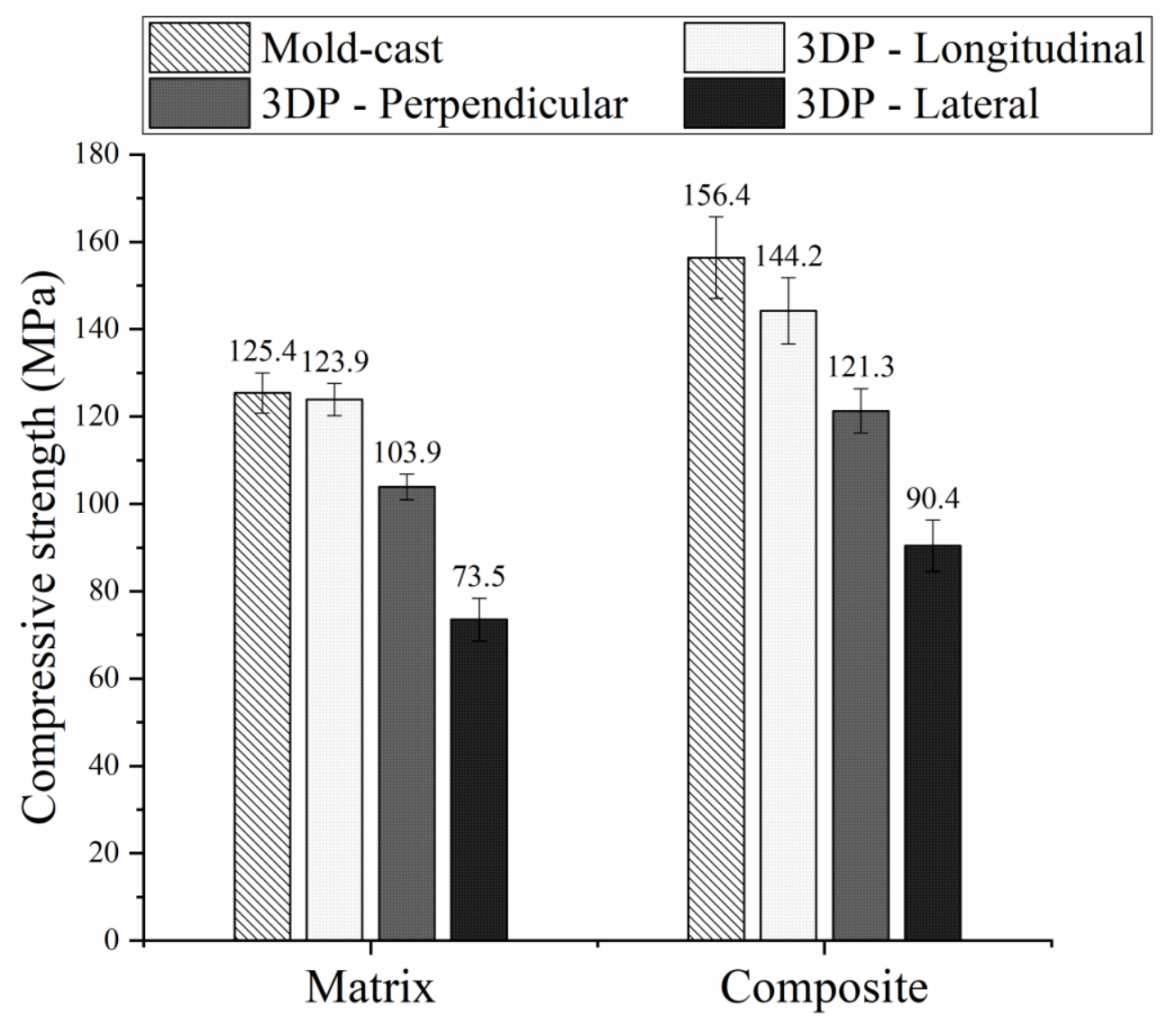

Figure 13 Compressive strength of the UHPFRC matrix and composite

The MOR results are presented in Figure 14. The MORs of the UHPFRC matrix and composite in the perpendicular direction are slightly higher than the respective MORs in the lateral direction. This is consistent with the previous studies where the primary load resisting component was either normal strength concrete [17], high performance concrete [10], or geopolymer concrete [7]. The bottom layer carrying the tensile stress during a flexural test was compacted more in the perpendicular direction compared to the lateral direction due to the selfweight of the top layer, which explains the greater MOR in the perpendicular direction compared to that in the lateral direction. 


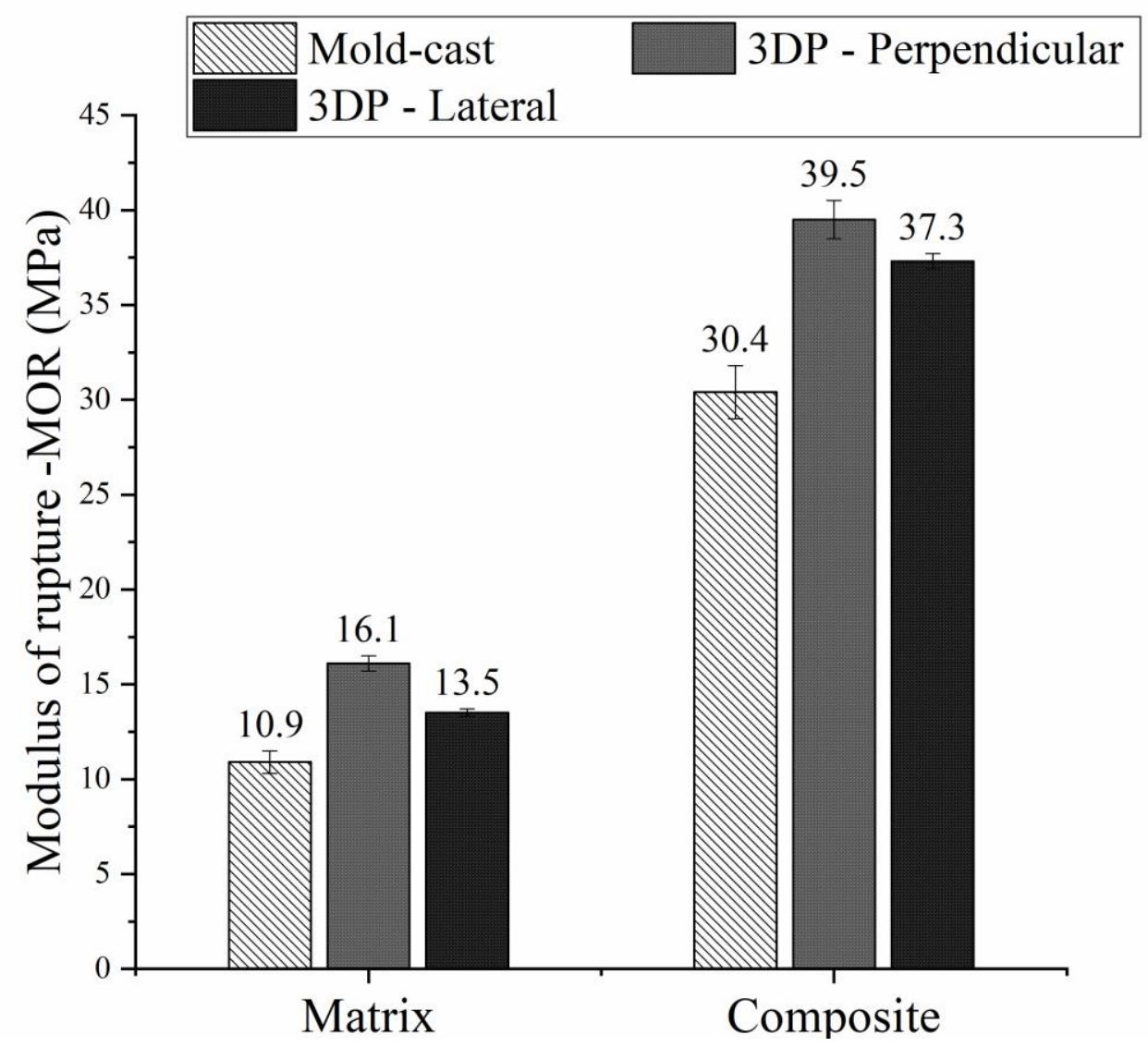

Figure 14 MOR of the UHPFRC matrix and composite

According to Figure 14, the MORs of the printed specimens are significantly higher than those of the mold-cast specimens. This observation is in contrast to the compressive strength results presented in Figure 13, which is attributed to the printing process. As pressure is exerted in the longitudinal direction during printing, the steel fibers tend to align in the direction of concrete flow (the longitudinal direction). The printing nozzle size of $15 \mathrm{~mm}$ - which is only slightly larger than the length of steel fiber $(13 \mathrm{~mm})$ - aligns the fibers in the plane of the layer. The alignment of short fibers in the printing direction due to the extrusion process has been reported in the literature for 3D printed fiber-reinforced geopolymer composites [13, 31] and strainhardening cementitious composites [32, 33]. On the other hand, the mold-cast specimens show a more random orientation of fibers in all the three dimensions [34]. 

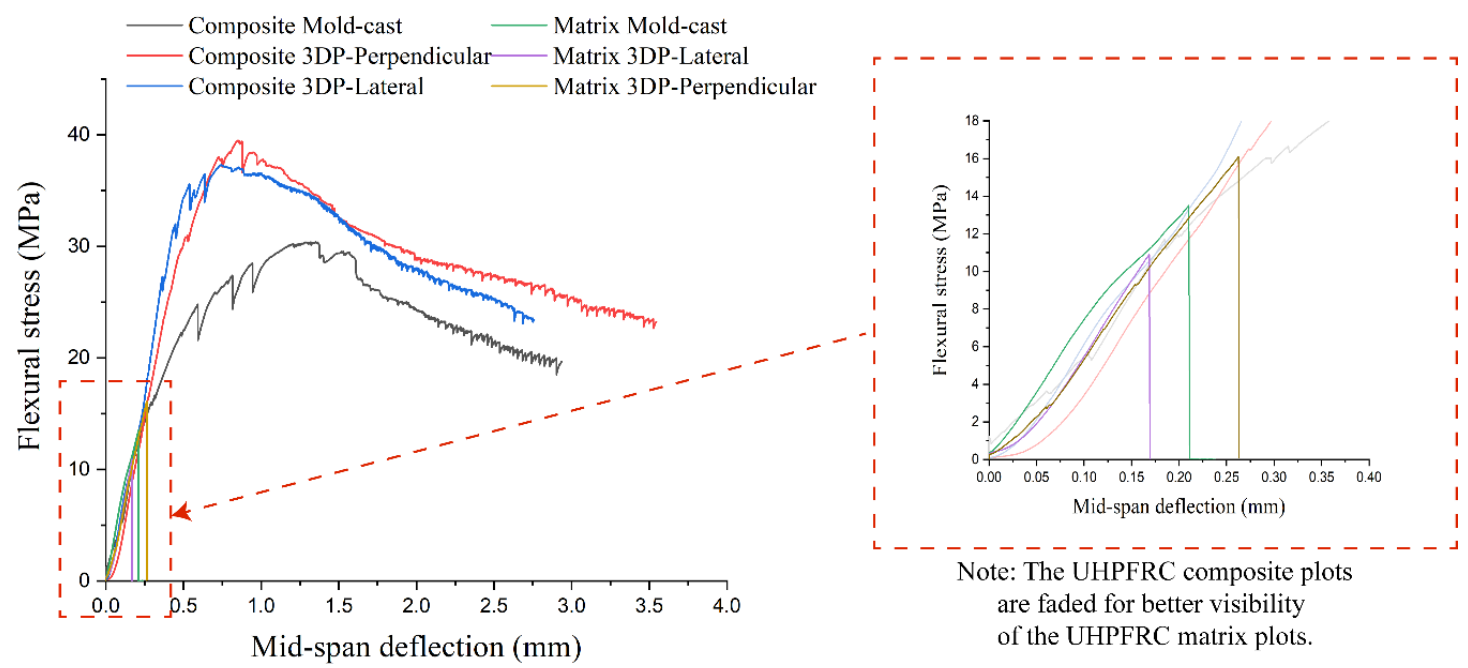

Figure 15 Flexural stress versus mid-span deflection graphs of the UHPFRC matrix and composite

Figure 15 presents the flexural stress versus mid-span deflection graphs for the UHPFRC matrix and composite specimens. The deflection-hardening effect of steel fiber reinforcement is clearly visible in this figure, as all the composite specimens exhibited significantly greater load carrying capacity (after first-crack) than the respective matrix specimens. Figure 16 presents the flexural toughness values calculated from the area under the flexural stress versus mid-span deflection curves presented in Figure 15 up to mid-span deflection of $2.5 \mathrm{~mm}$ or complete failure, whichever occurs first. The superior flexural performance of the 3D printed UHPFRC to conventional mold-cast UHPFRC can be clearly seen in Figures 18 and 19. Furthermore, Figure 16 shows that the flexural toughness of the UHPFRC composites are about 1-2 orders of magnitude greater than the respective matrices. 


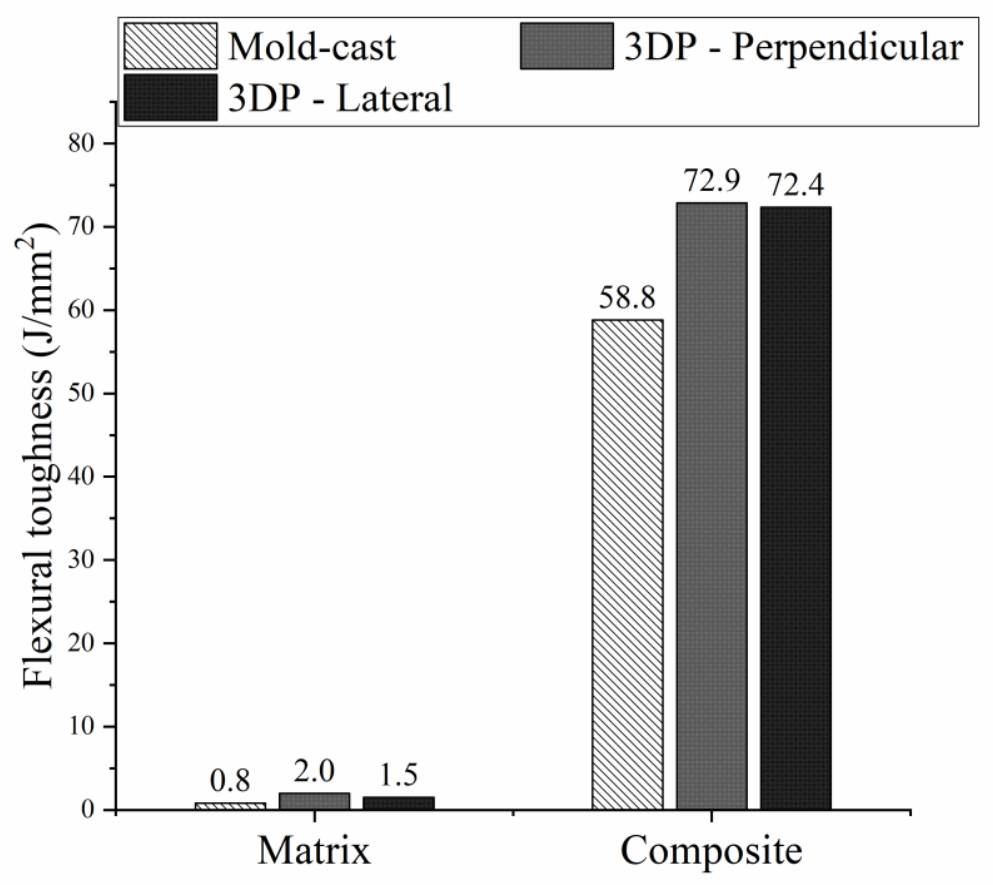

Figure 16 Flexural toughness of UHPFRC matrix and composites

The inter-layer bond strength results are presented in Figure 17. The UHPFRC composite shows stronger bonding between the layers than the matrix. This shows that the inclusion of fibers improves the inter-layer bond strength, despite the fiber orientation being predominantly parallel to the inter-layer surface. Figure 18 shows the inter-layer bond stress versus displacement curves of the UHPFRC matrix and composite samples. Unlike the UHPFRC matrix sample, a displacement-hardening behavior was noticed in the UHPFRC composite specimen, which may be attributed to the development of multiple fine cracks in the printed layers adjacent to the inter-layer surface. When the inter-layer surface cracked, it still failed in a brittle manner as observed by the sudden drop of load in the composite specimen at the end of the stress-displacement curve in Figure 18, which supports the fact that there were no fibers bridging across the inter-layer surface. It should be noted that the observed significantly higher inter-layer bond strength in the printed UHPFRC composite as compared to that of the printed UHPFRC matrix shall be investigated comprehensively in our future research. The inter-layer bond strength of the UHPFRC observed in this study is significantly higher than the values reported in the literature for normal strength concrete [35], geopolymer concrete [8, 36], fiber- 
reinforced concrete [12], fiber-reinforced geopolymer concrete [13] due to the superior mechanical properties of the UHPFRC.

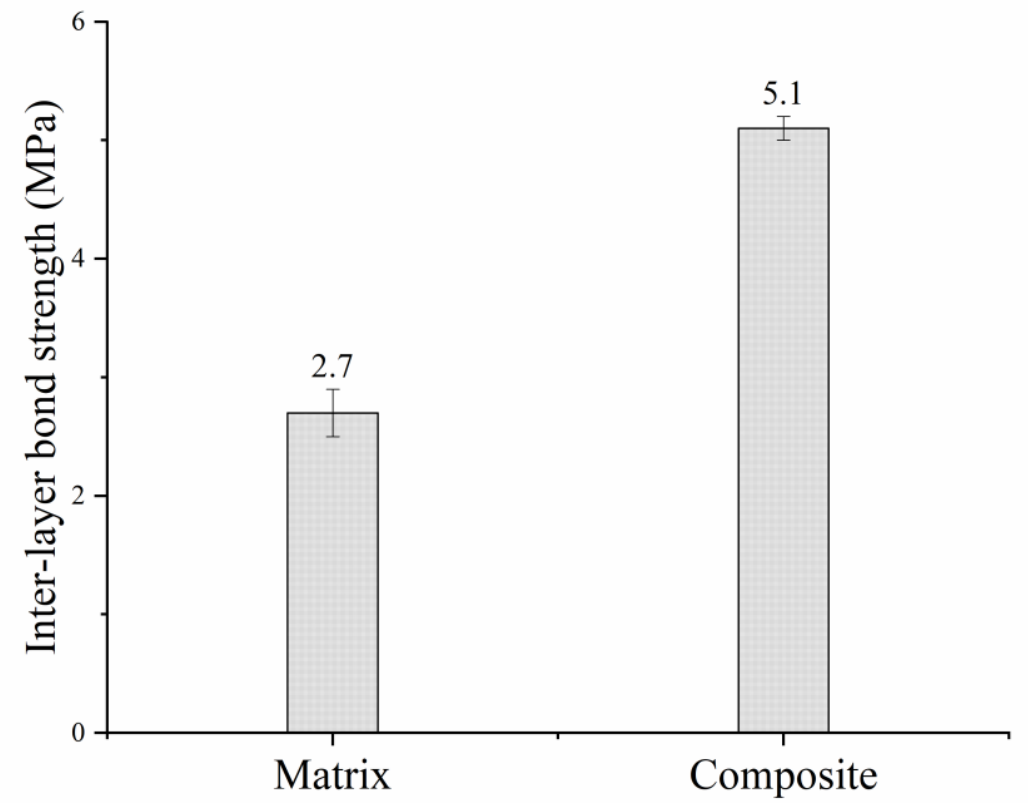

Figure 17 Inter-layer bond strength of 3D-printed UHPFRC matrix and composite

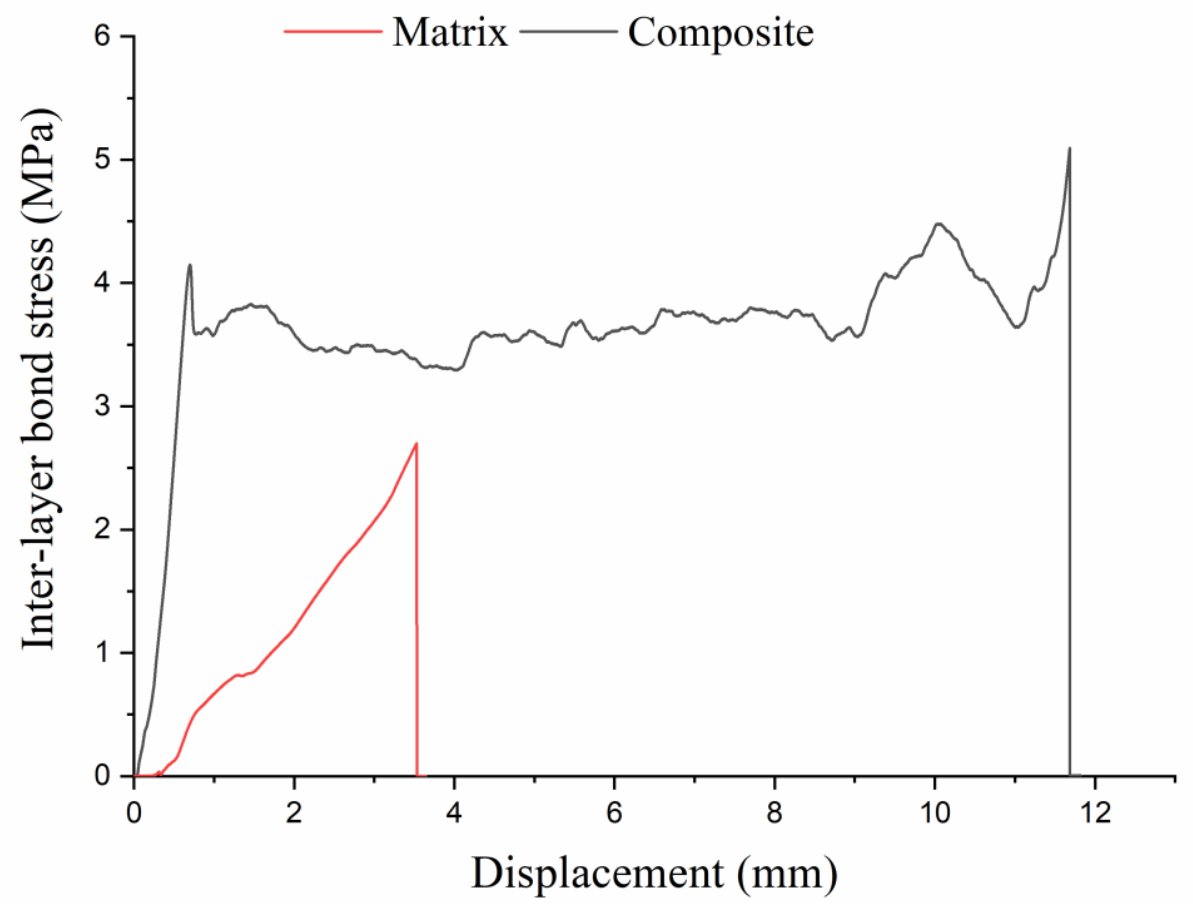

Figure 18 Inter-layer bond stress versus displacement curves of 3D-printed UHPFRC matrix and composite 
Figure 19 shows the apparent porosities of the UHPFRC matrix and composite. For both the mold-cast and 3D-printed UHPFRCs, the apparent porosity of the composite samples was significantly higher than that of the matrix. This is due to a fiber-induced damage effect causing greater air entrapment in the composite sample, and thereby higher porosity of the composite than the matrix [37]. Similar results were reported for strain-hardening geopolymer composites reinforced by different polymeric fibers $[38,39]$. For both the matrix and composite samples, the apparent porosity of the 3D-printed UHPFRC was slightly higher than that of the mold-cast UHPFRC. This is due to the unconfined lateral expansion and the lack of vibration and compaction in the 3D-printed UHPFRC samples.

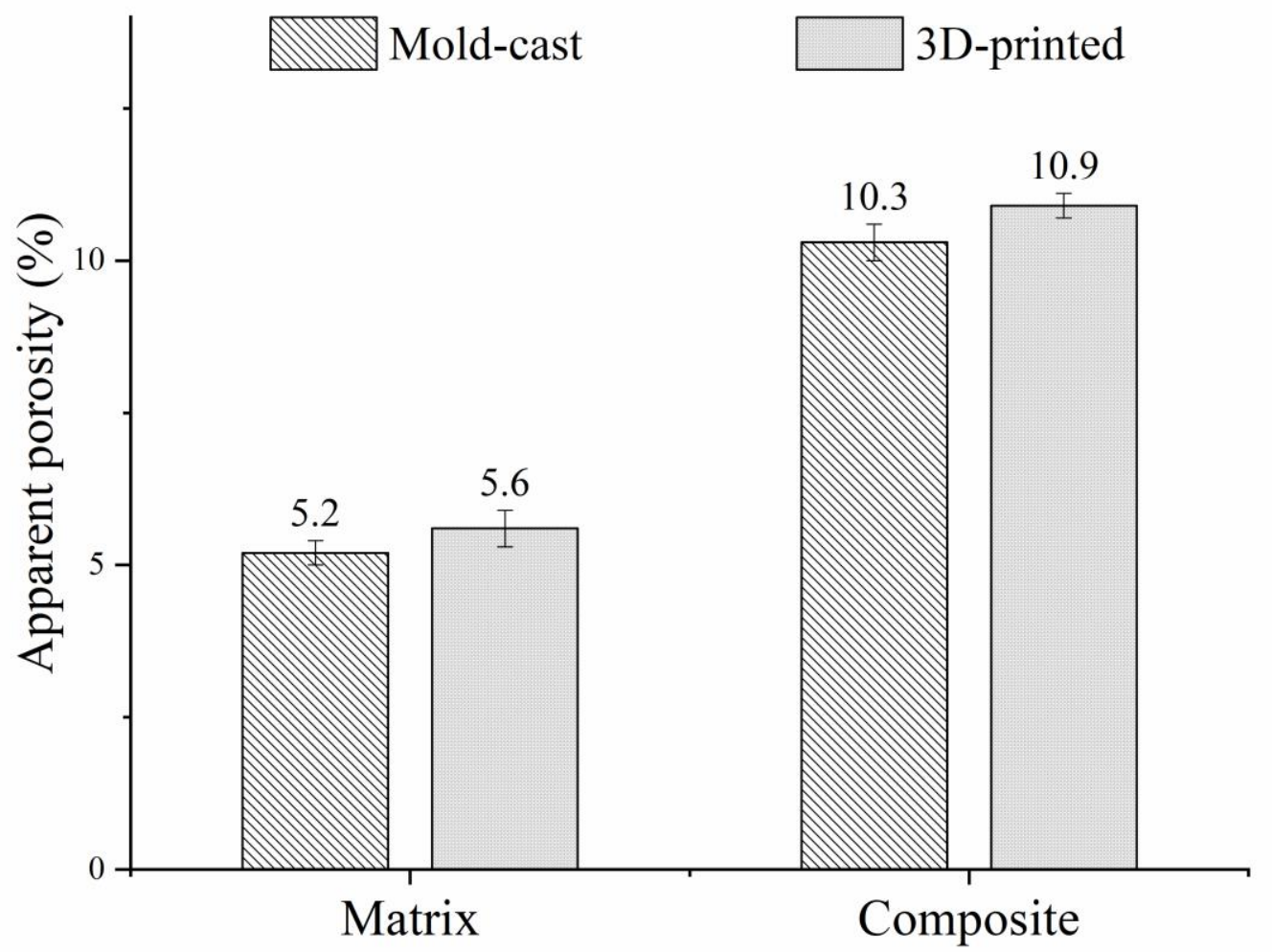

Figure 19 Apparent porosity of the UHPFRC matrix and composite 


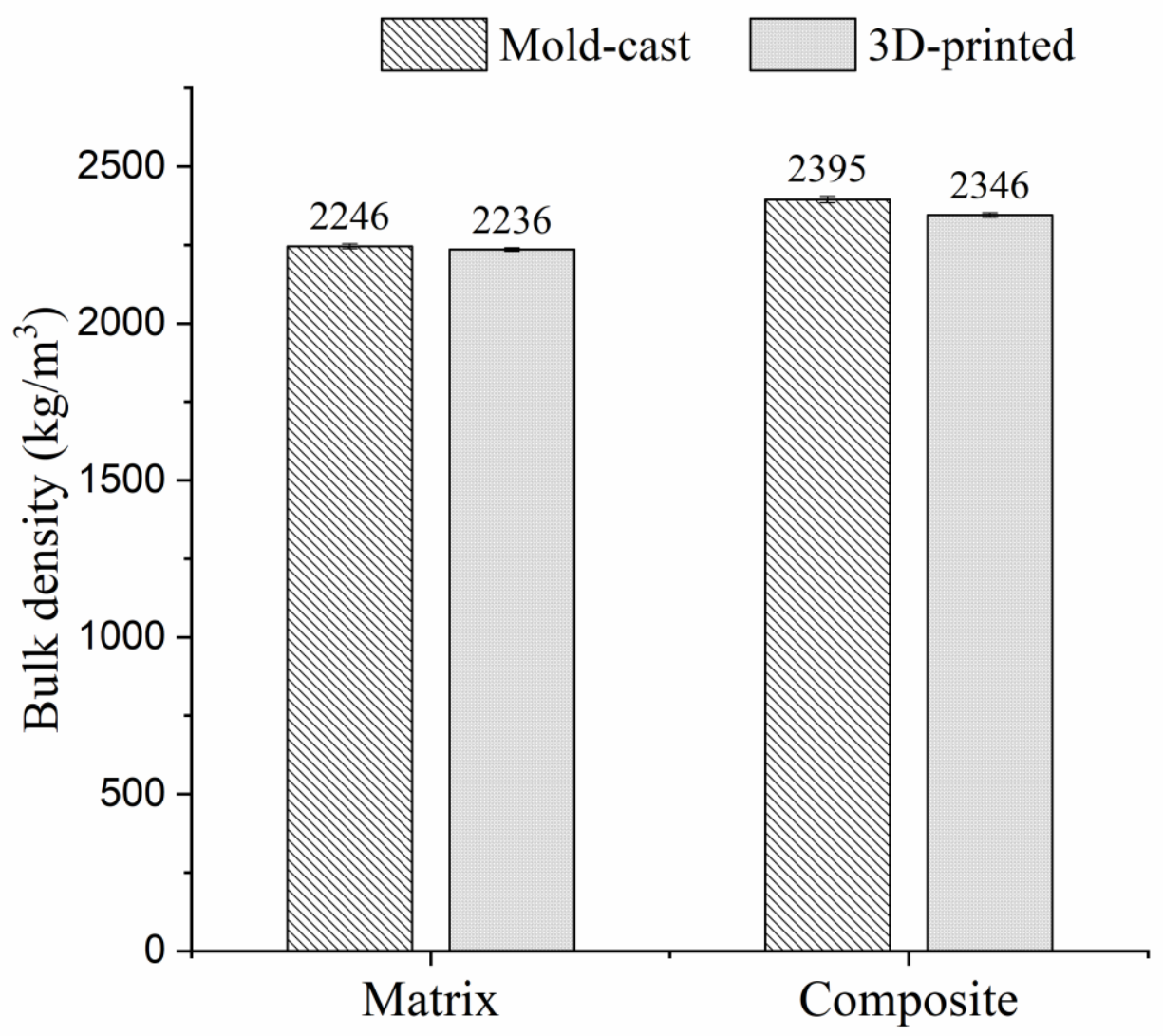

Figure 20 Bulk density of the hardened UHPFRC matrix and composite

The bulk densities of the UHPFRC matrix and composite are presented in Figure 20. For both the mold-cast and 3D-printed UHPFRCs, the density of the composite samples was slightly higher than that of the corresponding matrix due to the high density of the steel fibers. For both the matrix and composite samples, the density of the 3D-printed UHPFRC was slightly lower than that of the mold-cast UHPFRC. This result is in agreement with the slightly higher porosity of the printed UHPFRC specimens (see Figure 19).

\section{3D-printing a complex curvilinear component}

A relatively large-scale component with a complex geometry was 3D-printed to ascertain the applicability of the developed 3D-printable UHPFRC in practice. In this regard, a gantry printer with an effective printing space of $1.8 \mathrm{~m} \times 1.6 \mathrm{~m} \times 1.8 \mathrm{~m}$ was used. An augur type extruder with a circular nozzle of $30 \mathrm{~mm}$ diameter was attached to the gantry system. The printing speed and extrusion rate of the printer were $30 \mathrm{~mm} / \mathrm{s}$ and $1.3 \mathrm{~L} / \mathrm{min}$. The fresh UHPFRC composite was 
successfully extruded through the nozzle in a single attempt without any obstruction caused by blockage, tearing, segregation or bleeding. Figure 21 shows the printed structure consisted of 25 layers. The length of each layer was approximately $2 \mathrm{~m}$ and the layer height was about $10 \mathrm{~mm}$. From the elevation view of the layers, no signs of vertical distortion, layer failure or excessive deformation were observed in the built-up layers. Thus, the suitability of the developed 3Dprintable UHPFRC for production of relatively large-scale component with complex geometries is experimentally established. The detailed test results of the printed curvilinear structure will be published in a future article.
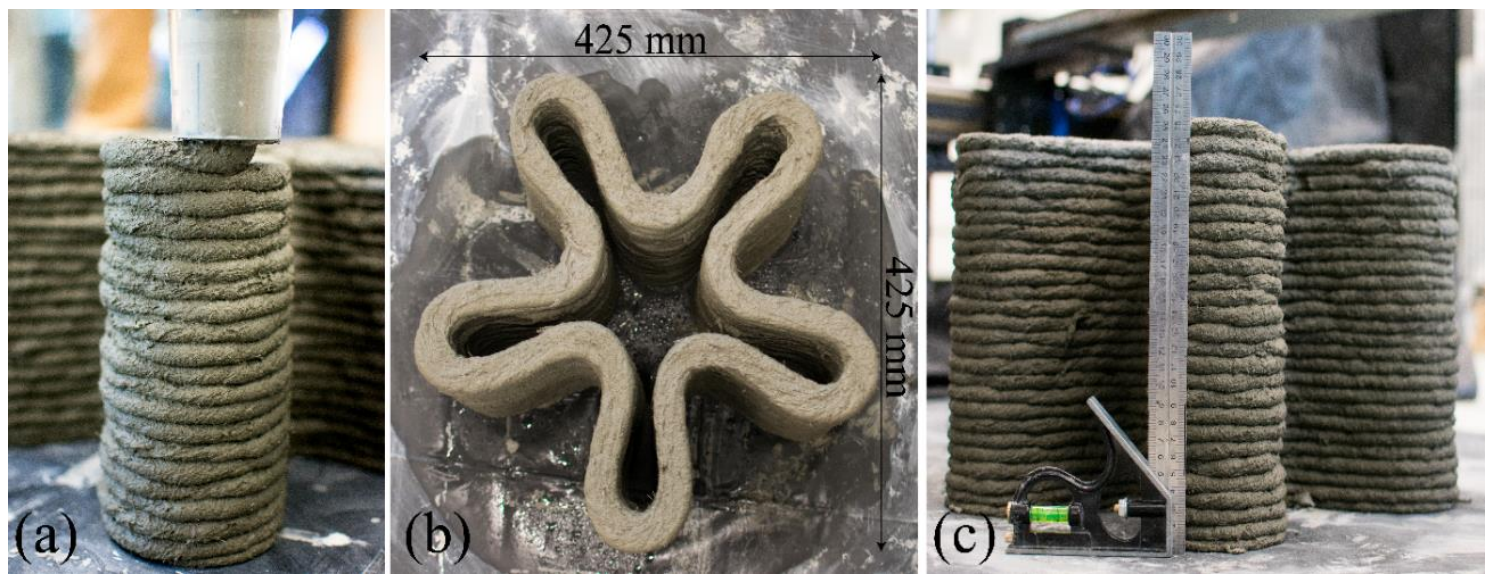

Figure 21 3D printing of a complex curvilinear component using the developed 3D-printable

UHPFRC mixture: (a) during 3D-printing process; (b) top-view; and (c) side-view

\section{Conclusions}

This study demonstrates the mix design development and performance characterization of a non-proprietary 3D-printable ultra-high-performance fiber-reinforced concrete (UHPFRC) mixture for 3D construction printing applications. Conventionally mold-cast UHPFRC matrix and composite were prepared for comparison purposes. The fresh properties of workability, extrudability, buildability, and shape-retention-ability of the developed 3D-printable UHPFRC matrix (without fibers) and composite (with steel fibers) were investigated. The hardened properties of compressive, flexural and inter-layer bond strengths, as well as apparent porosity 
and bulk density of the developed 3D-printable UHPFRC matrix and composite were measured. Further, effects of the loading direction on the compressive and flexural strengths of the printed UHPFRC matrix and composite were also studied. The main conclusions of the study are:

1. The presence of short straight steel fibers in the 3D-printable UHPFRC influenced its fresh properties. While the workability of the UHPFRC composite was slightly lower than that of the UHPFRC matrix, the shape-retention-ability of the composite was significantly better than that of the matrix. Both the UHPFRC matrix and composite had good extrudability and buildability based on the qualitative criteria selected in this study.

2. (a) The compressive strength, modulus of rupture (MOR) and flexural toughness of the developed UHPFRC composite were significantly enhanced due to the addition of short steel fibers as compared to those of the UHPFRC matrix. All UHPFRC composite samples exhibited clear deflection-hardening behavior in bending. (b) However, the apparent porosity also increased with the addition of the steel fibers. Both (a) and (b) are true for both the mold-cast and 3D-printed UHPFRCs.

3. The compressive strength of the printed UHPFRC was dependent on the loading direction. It was the highest in the longitudinal direction, followed by that in the perpendicular direction, and the strength was the lowest in the lateral direction of loading. This pattern is true for both the matrix and composite specimens. The compressive strength of the moldcast UHPFRC was higher than the printed UHPFRC, which is also true for both the matrix and composite samples. This is due to better compaction and confinement of the mold-cast specimens.

4. For both the matrix and composite samples, the MOR of the printed UHPFRC in the perpendicular direction was slightly higher than that in the lateral direction. In contrast to the compressive strength results, the printed UHPFRC samples exhibited superior flexural performance to the mold-cast UHPFRC samples. The MORs of the printed UHPFRC specimens in both perpendicular and lateral directions were significantly higher than those of the mold-cast specimens. This is attributed to the alignment of short fibers in the printing 
direction during the extrusion process, resulting in the $2 \mathrm{D}$ orientation of steel fibers in the plane of the printed layers, as opposed to a more random 3D fiber distribution in the moldcast specimens.

5. The inter-layer bond strength of the printed UHPFRC composite was significantly higher than that of the matrix, despite the fact that there was no apparent bridging of the inter-layer surfaces by the steel fibers. Further research is needed to fully understand the underlying reasons for this behavior.

\section{Acknowledgements}

The work was supported by the Australian Research Council Linkage Infrastructure Grant LE170100168 and Discovery Early Career Researcher Award DE180101587. The materials used in this research were supplied by Building Products Supplies Pty Ltd, Doral Pty Ltd, TGS Industrial Sand Ltd, BASF, DKS Co. Ltd, and Bekaert. The authors are grateful to all the material suppliers.

\section{References}

[1] Bos F, Wolfs R, Ahmed Z, Salet T. Additive manufacturing of concrete in construction: potentials and challenges of 3D concrete printing. Virtual Phys Prototyp 2016;11(3):20925.

[2] Buswell RA, de Silva WL, Jones S, Dirrenberger J. 3D printing using concrete extrusion: A roadmap for research. Cement Concr Res 2018;112:37-49.

[3] Nematollahi B, Xia M, Sanjayan J. Current progress of 3D concrete printing technologies. In: Proceedings of ISARC-34 International Symposium on Automation and Robotics in Construction. Taiwan, June, 2017. p.260-7.

[4] Ngo TD, Kashani A, Imbalzano G, Nguyen KT, Hui D. Additive manufacturing (3D printing): A review of materials, methods, applications and challenges. Compos B Eng 2018;143:172-96.

[5] Wangler T, Roussel N, Bos FP, Salet TA, Flatt RJ. Digital concrete: a review. Cement Concr Res 2019;123:105780.

[6] Perrot A, Rangeard D, Pierre A. Structural built-up of cement-based materials used for 3D-printing extrusion techniques. Mater Struct 2016;49(4):1213-20.

[7] Sanjayan JG, Nematollahi B, Xia M, Marchment T. Effect of surface moisture on interlayer strength of 3D printed concrete. Constr Build Mater 2018;172:468-75.

[8] Bong SH, Nematollahi B, Nazari A, Xia M, Sanjayan J. Method of Optimisation for Ambient Temperature Cured Sustainable Geopolymers for 3D Printing Construction Applications. Mater 2019;12(6):902.

[9] Panda B, Unluer C, Tan MJ. Extrusion and rheology characterization of geopolymer nanocomposites used in 3D printing. Compos B Eng 2019;176:107290. 
[10] Perrot A, Rangeard D, Courteille E. 3D printing of earth-based materials: Processing aspects. Constr Build Mater 2018;172:670-6.

[11] Le TT, Austin SA, Lim S, Buswell RA, Gibb AG, Thorpe T. Mix design and fresh properties for high-performance printing concrete. Mater Struct 2012;45(8):1221-32.

[12] Le TT, Austin SA, Lim S, Buswell RA, Law R, Gibb AG, et al. Hardened properties of high-performance printing concrete. Cement Concr Res 2012;42(3):558-66.

[13] Nematollahi B, Vijay P, Sanjayan J, Nazari A, Xia M, Naidu Nerella V, et al. Effect of Polypropylene Fibre Addition on Properties of Geopolymers Made by 3D Printing for Digital Construction. Mater 2018;11(12):2352.

[14] Panda B, Paul SC, Tan MJ. Anisotropic mechanical performance of 3D printed fiber reinforced sustainable construction material. Mater Lett 2017;209:146-9.

[15] Bos F, Bosco E, Salet T. Ductility of 3D printed concrete reinforced with short straight steel fibers. Virtual Phys Prototyp 2018:1-15.

[16] Gosselin C, Duballet R, Roux P, Gaudillière N, Dirrenberger J, Morel P. Large-scale 3D printing of ultra-high performance concrete-a new processing route for architects and builders. Mater. Des 2016;100:102-9.

[17] AS 3972. General Purpose and Blended Cements. Standards Australia. 2010.

[18] AS 3582.3. Supplementary cementitious materials for use with portland and blended cement. 2016.

[19] ASTM C136. Standard test method for sieve analysis of fine and coarse aggregates. 2006.

[20] Funk JE, Dinger DR. Predictive process control of crowded particulate suspensions: applied to ceramic manufacturing: Springer Science \& Business Media; 2013.

[21] Hüsken G, Brouwers H. A new mix design concept for earth-moist concrete: A theoretical and experimental study. Cement Concr Res 2008;38(10):1246-59.

[22] Yu Q, Spiesz P, Brouwers H. Development of cement-based lightweight compositesPart 1: mix design methodology and hardened properties. Cem Concr Compos 2013;44:17-29.

[23] Hunger M. An integral design concept for ecological self-compacting concrete: Doctoral dissertation. Eindhoven University of Technology, The Netherlands; 2010.

[24] Ragalwar KA, Nguyen H, Ranade R, Heard WF, Williams BA. Influence of Distribution Modulus of Particle Size Distribution on Rheological and Mechanical Properties of Ultra-High-Strength SHCC Matrix. In: Proceedings of SHHC-4 International Conference on Strain-Hardening Cement-Based Composites. RILEM; Dresden, September, 2017. p.221-9.

[25] Yu R, Spiesz P, Brouwers H. Mix design and properties assessment of ultra-high performance fibre reinforced concrete (UHPFRC). Cement Concr Res 2014;56:29-39.

[26] Ranade R, Stults MD, Li VC, Rushing TS, Ronth J, Heard WF. Development of high strength high ductility concrete. In: Proceedings of SHHC-2 International Conference on Strain-Hardening Cementitious Composites. RILEM; Rio de Janeiro, December, 2011. p.1-8.

[27] ASTM C1437. Standard test method for flow of hydraulic cement mortar. 2007.

[28] ASTM C20. Standard test methods for apparent porosity, water absorption, apparent specific gravity, and bulk density of burned refractory brick and shapes by boiling water. 2015.

[29] Tay YWD, Qian Y, Tan MJ. Printability region for 3D concrete printing using slump and slump flow test. Compos B Eng. 2019:106968.

[30] Nematollahi B, Xia M, Bong SH, Sanjayan J. Hardened Properties of 3D Printable 'One-Part' Geopolymer for Construction Applications. In: Proceedings of International Conference on Concrete and Digital Fabrication: RILEM; Zurich, September, 2018. p.190-9.

[31] Bong SH, Nematollahi B, Xia M, Nazari A, Sanjayan J, Pan J. Properties of 3DPrintable Ductile Fibre-Reinforced Geopolymer Composite for Digital Construction Applications. In: Proceedings of Rheology and Processing of Construction Materials: RILEM; Dresden, September, 2019. p.363-72. 
[32] Ogura H, Nerella V, Mechtcherine V. Developing and testing of strain-hardening cement-based composites (SHCC) in the context of 3D-printing. Mater 2018;11(8):1375.

[33] Zhu B, Pan J, Nematollahi B, Zhou Z, Zhang Y, Sanjayan J. Development of 3D printable engineered cementitious composites with ultra-high tensile ductility for digital construction. Mater Des 2019;181:108088.

[34] Kang ST, Lee BY, Kim J-K, Kim YY. The effect of fibre distribution characteristics on the flexural strength of steel fibre-reinforced ultra high strength concrete. Constr Build Mater 2011;25(5):2450-7.

[35] Marchment T, Sanjayan J, Xia M. Method of enhancing interlayer bond strength in construction scale 3D printing with mortar by effective bond area amplification. Mater Des 2019:107684.

[36] Panda B, Ruan S, Unluer C, Tan MJ. Improving the 3D printability of high volume fly ash mixtures via the use of nano attapulgite clay. Compos B Eng 2019;165:75-83.

[37] Nematollahi B, Sanjayan J, Shaikh FUA. Comparative deflection hardening behavior of short fiber reinforced geopolymer composites. Constr Build Mater 2014;70:54-64.

[38] Nematollahi B, Sanjayan J, Qiu J, Yang E-H. Micromechanics-based investigation of a sustainable ambient temperature cured one-part strain hardening geopolymer composite. Constr Build Mater 2017;131:552-63.

[39] Nematollahi B, Sanjayan J, Shaikh FUA. Matrix design of strain hardening fiber reinforced engineered geopolymer composite. Compos B Eng 2016;89:253-65. 